\title{
Correction to: Pathophysiological Clues to how the Emergent SARS-CoV-2 Can Potentially Increase the Susceptibility to Neurodegeneration
}

\author{
Mahsa Dolatshahi ${ }^{1,2}\left(\right.$ Mohammadmahdi Sabahi $^{2,3} \cdot$ Mohammad Hadi Aarabi $^{4,5}$
}

Published online: 27 January 2021

(C) Springer Science+Business Media, LLC, part of Springer Nature 2021

\section{Correction to: Mol Neurobiol.}

https://doi.org/10.1007/s12035-020-02236-2

The original version of this article unfortunately contained some mistakes.

Assignment of affiliation number to "MohammadHadi Aarabi" is incorrect. Dr. MohammadHadi Aarabi is affiliated to:

"MohammadHadi Aarabi 4" should be "Mohammad Hadi Aarabi 4,5".

4 Department of Neuroscience, University of Padova, Padova, Italy 5 Padova Neuroscience Center (PNC), University of Padova, Padova, Italy

The original paper has been corrected.

Publisher's Note Springer Nature remains neutral with regard to jurisdictional claims in published maps and institutional affiliations.

The online version of the original article can be found at https://doi.org/ $10.1007 / \mathrm{s} 12035-020-02236-2$

Mahsa Dolatshahi

Dolatshahimahsa75@gmail.com

Mohammadmahdi Sabahi

m.sabahi@edu.umsha.ac.ir

Mohammad Hadi Aarabi

mohammadhadiarabi@gmail.com

1 Students' Scientific Research Center (SSRC), Tehran University of Medical Sciences, Tehran, Iran

2 NeuroImaging Network (NIN), Universal Scientific Education and Research Network (USERN), Tehran, Iran

3 Neurosurgery Research Group (NRG), Student Research Committee, Hamadan University of Medical Sciences, Hamadan, Iran

4 Department of Neuroscience, University of Padova, Padova, Italy

5 Padova Neuroscience Center (PNC), University of Padova, Padova, Italy 